\title{
LOS EFECTOS DE LA TRANSPARENCIA EN EL ÁMBITO LOCAL. UN ANÁLISIS EN PERSPECTIVA DE FUTURO
}

The effects of transparency in the local field. An analysis in future perspective

DOI: http://dx.doi.org/10.15304/dereito.27.Ext.5791

"Si hace veinte años hubiéramos hecho una evaluación de la transparencia existente en los municipios españoles el resultado hubiera sido demoledor" M. VILLORIA MENDIETA ${ }^{1}$

ConCEPCiÓn CAMPos ACUÑA

Secretaria de Gobierno Local

Concello de Vigo

concepcioncamposacunha@gmail.com

\section{Resumen}

La aprobación de la LETAI ha supuesto un punto de inflexión en la organización y funcionamiento de las administraciones públicas, como una medida de regeneración democrática que permita una adecuada rendición de cuentas y el camino hacia el gobierno abierto a través de la transparencia, la participación y la colaboración. Esta transformación presenta especiales dificultades en el ámbito local, dada la compleja configuración de la planta local y la escasez de recursos personales y materiales de las entidades locales. En el presente trabajo se analiza el impacto de la transparencia en el ámbito local a través de los distintos elementos que lo integran, desde la perspectiva de la normativa básica, la autonómica y los objetivos de futuro para las entidades que integran la administración local.

Palabras clave: Transparencia, administración local, buen gobierno.

\section{Abstract}

The adoption of LETAI has meant a turning point in the Organization and operation of public administrations, as a measure of democratic regeneration, that allow a proper accountability and the road to the Government open through transparency, participation and collaboration. This transformation presents special difficulties at the local level, given the complex configuration of the local plant and the shortage of material and personal resources of local authorities. This paper analyzes the impact of transparency at the local level through the various elements that compose it, from the perspective of basic legislation, the regional and the future

\footnotetext{
1 "El largo camino hacia la transparencia en los Ayuntamientos españoles", Consultor de los ayuntamientos, Monográfico dedicado a la transparencia en la actividad municipal, núm. 18, 2015, pp. 1983-2001.
}

Recibido: 10/12/2017. Aceptado: 09/09/2018. 
objectives for institutions that make up the local administration. Keywords: transparency, local administration, good governance.

\section{SUMARIO}

1. LAS ENTIDADES LOCALES ANTE EL MARCO NORMATIVO DE LA TRANSPARENCIA. CONDICIONES DE IMPLANTACIÓN.;- 1.1. La transparencia local antes y después de la Ley 19/2013.;- 1.2. Desafíos de la planta local y la administración electrónica. 1.3. Las fórmulas colaborativas como eje de la implantación: las Diputaciones, una propuesta nada iconoclasta.;- 2. LA TRANSPARENCIA COMO UN ELEMENTO TRANSVERSAL A LA ORGANIZACIÓN MUNICIPAL.;- 2.1. Efectos y consecuencias de la publicidad activa.;- 2.2. Efectos de la publicidad pasiva: el modelo de control en el ejercicio del derecho de acceso a la información.;- 3. EL BUEN GOBIERNO EN CLAVE LOCAL: POLÍTICAS DE REGENERACIÓN DEMOCRÁTICA.;- 3.1. Los códigos éticos o de conducta como instrumentos al servicio de la transparencia.;- 3.2. El buen gobierno en la Ley de Transparencia.;- 4. EL IMPACTO DE LA NORMATIVA AUTONÓMICA EN LA TRANSPARENCIA LOCAL.;- 4.1. Las Entidades Locales como sujetos activos de la transparencia autonómica.;4.2. Especial referencia a la Ley 1/2016, de Transparencia y Buen Gobierno de Galicia (LGT).;- 5. RETOS DE FUTURO PARA LOS GOBIERNOS LOCALES.;- 5.1.La transformación digital: sinergias derivadas de la reforma de la Administración.;- 5.2. La reutilización de datos como vía para generar valor público.;- 5.3. El desarrollo del gobierno abierto a través de la participación ciudadana.;- 6. BIBLIOGRAFÍA.

\section{LAS ENTIDADES LOCALES ANTE EL MARCO NORMATIVO DE LA TRANSPARENCIA. CONDICIONES DE IMPLANTACIÓN}

La aprobación de la LETAI supuso un relevante punto de inflexión en el marco normativo de las obligaciones de transparencia, en particular, desde la consideración del derecho comparado, cuando en nuestro entorno no eran pocos los países que contaban ya con larga tradición normativa en esta materia.

Sin embargo, su naturaleza de norma básica para el conjunto de las Administraciones Públicas, estatal, autonómica y local, exige una consideración previa de las particulares condiciones de partida en el ámbito local para su implantación, que condicionan en un grado elevado las posibilidades de implantación de la normativa.

\subsection{La transparencia local antes y después de la Ley 19/2013}

Decíamos que la LETAI supuso un marco de inflexión en las obligaciones de transparencia, pero no se trata de un tema inédito, nuestro ordenamiento jurídico contaba ya con numerosas previsiones normativas en esta materia, tal y como apunta la propia LETAI en su Exposición de Motivos, cuando señala que "no parte de la nada ni colma un vacío absoluto". Es decir, la publicidad activa y el derecho de acceso a la información pública eran ya una realidad en nuestro ordenamiento jurídico con anterioridad a la LETAI y siguen existiendo al margen de la misma, de 
tal modo que para dar debido cumplimiento a la obligación de convertirnos en una administración transparente, no será suficiente con contemplar la información referida en la normativa sobre transparencia, estatal, autonómica o local, sino también en las demás normas del ordenamiento jurídico que contemplan otras obligaciones de corte sectorial ${ }^{2}$.

Al margen de los precedentes existentes en materia del derecho de acceso a la información, derivados de la disposición constitucional recogida en el artículo 105.b) y, sin perjuicio de las disquisiciones sobre la adecuada configuración del derecho como fundamental o no, de relevancia en atención al proceso de ponderación a la hora de facilitar el acceso, este derecho se contemplaba ya, con carácter general en la Ley 30/1992, de 26 de noviembre, de Régimen Jurídico de las Administraciones Públicas y del Procedimiento Administrativo Común (LRJPAC) y demás especialidades normativas ${ }^{3}$.

Desde ese punto de vista y concretado al ámbito local podemos detectar una serie de segmentos de la actividad municipal que se encuentran fuertemente marcados por las obligaciones de publicidad, como el relativo a la organización de la corporación y al régimen de los miembros de las corporaciones locales o al empleo público en el Real Decreto Legislativo $5 / 2015$, de 30 de octubre, por el que se aprueba el Texto Refundido de la Ley del estatuto básico del empleado público, la normativa en materia de medioambiente, sin olvidar la normativa autonómica sobre régimen local ${ }^{4}$. Dicha previsión debe completarse con dos matices, la inclusión de la información cuyo acceso se solicite con mayor frecuencia, $y$, sin perjuicio de la posibilidad de adoptar otras medidas complementarias y de colaboración para el cumplimiento de las obligaciones de transparencia recogidas en la normativa.

\subsection{Desafíos de la planta local y la administración electrónica}

Más de 8.000 ayuntamientos, entidades locales menores, diputaciones provinciales, consejos y cabildos insulares, mancomunidades, consorcios y comarcas, son un claro reflejo de la multitud de entidades que integran la

\footnotetext{
${ }^{2}$ M.C. CAMPOS ACUÑA, "Obligaciones de publicidad activa y su traslación al ámbito local. De la teoría a la práctica". Consultor de los ayuntamientos, Monográfico dedicado a la transparencia en la actividad municipal, núm. 18, 2015, pp. 2067-2083.

3 E. GUICHOT REINA. "Transparencia: Aspectos generales" en E. Guichot (coord.), Transparencia, Acceso a la Información Pública y Buen Gobierno, Tecnos, Madrid, 2014, pp. 35-52. Técnica que se conserva en la norma que la sustituye, la nueva normativa en materia de procedimiento administrativo común.

${ }^{4}$ A título meramente ejemplificativo recordar que el artículo 54 de la Ley 5/2010, de 11 de junio, de autonomía local de Andalucía contemplaba ya la obligación de publicar en su sede electrónica, o en su defecto, en la sede electrónica de la respectiva entidad, en el plazo de cinco días desde su adopción, las disposiciones y actos administrativos relativos a un nutrido grupo de materias y sin perjuicio de las especialidades en materia de derecho de acceso, como el relativo al derecho de los miembros de la Corporación, derivado de la propia configuración constitucional de su mandato representativo, tal y como recuerda M. M. RAZQUIN LIZARRAGA, en El derecho de acceso a la información pública, IVAP, Oñati, 2015.
} 
administración local, con sustanciales diferencias cualitativas entre todas ellas pero igualmente vinculadas por la LETAI.

Uno de los desafíos que con mayor claridad se planten en materia de transparencia es la falta de medios para la adecuada implantación de la administración electrónica, dada la conexión con las dificultades en cumplimiento normativo en materia de transparencia, ya que la publicidad activa se ejerce on line. Aunque ya es una realidad para muchas de las entidades locales, todavía son numerosas las que distan de estar en condiciones de asumir los retos derivados de la entrada en vigor de la Ley $39 / 2015$, de 1 de octubre, del procedimiento administrativo común de las administraciones públicas, y la Ley 40/2015, de 1 de octubre, de régimen jurídico del sector público ${ }^{5}$.

Esta conexión $y$, en consecuencia, la relevancia de la administración electrónica en la consecución de entidades locales transparentes deriva directamente de la LETAI, en cuyo artículo 5 establece el deber de que las obligaciones de publicidad activa se ejecuten a través de la sede electrónica o de la respectiva web municipal ${ }^{6}$.

\subsection{Las fórmulas colaborativas como eje de la implantación: las Diputaciones, una propuesta nada iconoclasta}

Tras la reforma efectuada en el régimen local por la Ley 27/2013, de 27 de diciembre, de racionalización y sostenibilidad de la administración local, asignando a las diputaciones provinciales como competencia propia, de carácter instrumental, la relativa a la administración electrónica en los municipios de menos de 20.000 habitantes, las entidades provinciales están llamadas a desempeñar un relevante papel en una materia como ésta, en la que la administración electrónica constituye uno de los ejes fundamentales de implantación.

La creación de portales de transparencia provinciales como plataformas de adhesión a través de las cuales los municipios puedan cumplir sus obligaciones sobre transparencia constituye un claro ejemplo del papel que estas entidades, cuya supervivencia y legitimidad en el esquema territorial del Estado es objeto de evaluación y revisión periódicamente,

\footnotetext{
${ }^{5}$ M.C. CAMPOS ACUÑA. "Las entidades locales ante las obligaciones de transparencia. Una primera aproximación a la Ley 19/2013, de transparencia, acceso a la información pública y buen gobierno", Revista electrónica CEMCI, núm. 22, 2014. http://revista.cemci.org/numero-23/pdf/tribuna-2-las-entidades-locales-ante-lasobligaciones-de-transparencia.pdf

6 Dicha ambivalencia debe ser criticada en relación con las prescripciones legales en torno a la existencia de la sede electrónica municipal, contemplada en el artículo 10 de la ley de acceso electrónico de los ciudadanos a los servicios públicos y que debe ser el elemento de referencia para las relaciones con la ciudadanía. En dicho sentido la Agencia Española de Protección de Datos en Dictamen CNS 6/2010 ha señalado que "conforme a lo que establece el artículo 12 de la Ley 11/2007, de 22 de junio, de Acceso Electrónico de los Ciudadanos a los Servicios Públicos, la sede electrónica será el canal ordinario para la difusión electrónica de la Administración con los ciudadanos, ya que es en el marco de la sede electrónica donde la Administración debe garantizar la calidad, la seguridad, la disponibilidad y la neutralidad de la información".
} 
pueden desarrollar para apoyar los objetivos de la LETAI. Sin perjuicio de su ejecución a través de otras fórmulas colaborativas, tal y como sucede en Galicia como examinaremos, u otras iniciativas como el "Portal de la Transparencia en la nube para entidades locales"7.

\section{LA TRANSPARENCIA COMO UN ELEMENTO TRANSVERSAL A LA ORGANIZACIÓN MUNICIPAL}

Las peculiaridades organizativas de las ENTIDADES LOCALES, consecuencia directa de la fragmentación y heterogeneidad de la planta local, constituyen una dificultad en el proceso de implantación de las obligaciones legales en materia de transparencia, en cuanto no permiten el diseño marco de un modelo exportable con carácter general a las entidades que integran la administración local ${ }^{8}$. A continuación examinaremos los principales puntos en relación con los aspectos teóricos y prácticos del proceso de implantación.

\subsection{La asignación de responsabilidades y la reorganización administrativa}

La inexistente referencia legal en la LETAI en relación a aspectos de carácter organizativo en el ámbito local resulta adecuada en coherencia con el respeto al principio de autonomía local y a su potestad de autoorganización ${ }^{9}$.

Pero, al margen de dicha consideración, la ejecución de las obligaciones de transparencia exigirá una doble atribución en materia de responsabilidad. La política, entendida como responsabilidad de gobierno, de impulsar y apoyar la implantación de la LETAI, dotando de medios suficientes a la entidad, adoptando las decisiones necesarias y gestionando el proyecto y que, ante la ausencia de una atribución concreta, corresponderá al Alcalde-Presidente de la Corporación en aplicación de la cláusula competencial residual. En cuanto a la responsabilidad administrativa, comprenderá la de asumir el liderazgo interno en la implantación, coordinando los diferentes servicios municipales, promoviendo las actuaciones de rediseño organizativo y de funcionamiento, en clave procedimental, exponiendo las necesidades en cada momento y poniendo de relieve los puntos débiles del proceso a

\footnotetext{
${ }^{7}$ Configurado como un proyecto del Ministerio de Hacienda y Administraciones Públicas basado en un Acuerdo Marco de Colaboración entre el Ministerio de Hacienda y Administraciones Públicas y la Federación Española de Municipios y Provincias (FEMP) para promover y facilitar el desarrollo de la LETAI en el ámbito local. Además de la creación del Portal de la Transparencia para las entidades locales que se suscriban al mismo, tiene como objetivo dotar de toda la infraestructura TIC necesaria para alojarlos en las condiciones de seguridad, interoperabilidad y accesibilidad. Ya se han adherido más de 1.300 entidades.

${ }^{8}$ M. ALMEIDA CERREDA, "La reforma de la planta, organización, articulación y estructura competencial de la administración local", VIII Congreso Asociación Española de Profesores de Derecho Administrativo, 2013.

${ }^{9}$ Así lo afirma E. GUICHOT REINA en "Derecho de acceso a la información pública en el ámbito local", El Consultor de los Ayuntamientos, Monográfico Transparencia en la actividad municipal (M. C. CAMPOS ACUÑA, coord.), núm. 18, 2015, pp. 1983-2001.
} 
través de su evaluación, tareas en las que resultará fundamental el papel de los funcionarios de administración local con habilitación de carácter nacional, dada su naturaleza de vector común en la totalidad de entidades locales ${ }^{10}$.

\subsection{Efectos y consecuencias de la publicidad activa}

Los datos relativos a las consultas ciudadanas del Portal de Transparencia del Estado, frente a las escasas solicitudes del derecho de acceso a la información permiten advertir el diferente impacto ciudadano de ambas caras de la transparencia: la publicidad activa y el derecho de acceso a la información pública ${ }^{11}$.

Frente a las dificultades en el ejercicio del derecho de acceso, la libre y anónima consulta de la información que recoge el Portal de Transparencia constituyen, sin duda, una de las razones de esta brecha. La publicidad activa se materializa así a través de la sede electrónica o página web municipal, aún cuando en la mayoría de entidades locales se ha generalizado la práctica de instaurar un Portal de Transparencia, como vía de acceso a la información recogida en los artículos 6 a 8 LETAI, para facilitar su sistematización ${ }^{12}$.

No obstante, en esta materia no han sido pocas las normativas autonómicas que han ampliado considerablemente el ámbito material de las obligaciones de publicidad activa, entre las más recientes, la Ley 2/2016, de 2 de abril, de instituciones locales de Euskadi, realiza un profundo reajuste de las obligaciones básicas a las peculiaridades del ámbito local, introduciendo nuevas consideraciones en su Título VI "Gobierno Abierto" y segmentando esta obligación por áreas temáticas ${ }^{13}$.

${ }^{10}$ El Borrador de Real Decreto por el que se regula el régimen jurídico de los funcionarios de administración local con habilitación de carácter nacional, de 18.12.2015, en su artículo 2.3 atribuye a los funcionarios de administración local con habilitación de carácter nacional las funciones necesarias, dentro de su ámbito de actuación, para garantizar el principio de transparencia y los principios de estabilidad presupuestaria y sostenibilidad económico-financiera.

11 Según la información proporcionada por el Portal de Transparencia de la Administración General del Estado, en el mes de mayo de 2016 hubo 5.232.123 consultas al Portal, frente a las sólo 5.198 solicitudes de acceso a la información.

12 El Portal de Transparencia aparece recogido en la LETAI como un mecanismo de carácter instrumental para garantizar la ejecución de las obligaciones de publicidad activa. La regulación, de carácter no básico en este punto, prevé en su art. 10 el desarrollo del Portal como una herramienta específica a través de la cual dar cumplimiento a las obligaciones legales en materia de transparencia y desarrollar la estrategia de cada entidad.

13 Facilitando de este modo su consulta mediante una mejor estructura que ofrece la claridad y accesibilidad reclamada por la normativa, y conforme a la siguiente clasificación: Información institucional y organizativa; información jurídico-normativa; información de políticas públicas locales y de la cartera de servicios; información sobre gestión pública; información sobre el personal al servicio de las entidades locales; información económico-financiera y presupuestaria e información de interés general. 


\subsection{Efectos de la publicidad pasiva: el modelo de control en el ejercicio del derecho de acceso a la información}

El artículo 12 LETAI reconoce el libre derecho de acceso a la información pública en términos generales como un derecho derivado del artículo 105 b) de la Constitución española, cuestión de naturaleza conceptual que ha sido objeto de numerosas críticas frente a la opción más adecuada de situar su anclaje constitucional en el artículo 20 por distintas razones. Entre ellas, por supuesto, la especial protección que dicha atribución conceptual le permitiría, pero sobre todo como una vía para garantizar su verdadero ejercicio por los ciudadanos ${ }^{14}$.

Desde la experiencia del recorrido que ofrece la andadura de la norma y sin perjuicio de las múltiples razones concurrentes, podríamos diagnosticar los factores más relevantes para explicar esta situación, que parten de un notable desconocimiento y falta de cultura de transparencia en la ciudadanía ${ }^{15}$; las dificultades administrativas, pues a pesar de la amplitud con la que la Ley define el derecho de acceso, su ejercicio constituye una auténtica carrera de obstáculos. Causas de inadmisión, límites y protección de datos, acceso parcial, son actores invitados al procedimiento de acceso que, en función de cómo se interpreten y apliquen, pueden vaciar de contenido el derecho a la información. Sin menospreciar las dificultades tecnológicas, en particular y más allá de las deficiencias en el diseño de las herramientas tecnológicas, una de las mayores críticas se produce por la exigencia de firma electrónica. Y por último, desconfianza, pues subyace en una total falta de credibilidad de la eficacia real de este derecho como una manifestación más de la falta de legitimidad y crisis de confianza en las instituciones públicas. En este aspecto resulta muy relevante la labor que está realizando el Consejo de Transparencia y Buen Gobierno, tanto a través de la publicación de criterios interpretativos como en la resolución de solicitudes concretas que ofrecen ya, vía impugnación judicial, los primeros pronunciamientos judiciales ${ }^{16}$.

14 Frente al modelo imperante en el derecho comparado y las numerosas voces doctrinales que fundamentadamente han recogido el mayor ajuste a la verdadera naturaleza jurídica del derecho de acceso como derecho fundamental. Sobre esta cuestión pueden consultarse entre otros E. GUICHOT REINA, en Transparencia, Acceso a la Información y Buen Gobierno. Estudio de la Ley 19/2013, de 9 de diciembre, Tecnos, Madrid, 2014; o L. RAMS RAMOS, "La transformación del derecho de acceso en España: de derecho de configuración legal a derecho fundamental", Revista Española de Derecho Administrativo, Cívitas-Thomson Reuters, núm. 160, 2013.

15 Según el informe AEVAL 2016 "Estabilidad y mejoría en los servicios públicos", pasados casi dos años desde la aprobación de la Ley 19/2013 (en el momento de elaboración del informe), la mitad de la población desconoce la existencia de la LETAI, nivel de conocimiento que todavía es inferior con relación al Consejo de Transparencia y tan sólo un $22 \%$ de los ciudadanos afirma conocer el Portal de Transparencia, dato extremadamente bajo, y que todavía resulta más reducido si se toma en cuenta los datos relativos al porcentaje de ciudadanos que afirman haberlo utilizado en alguna ocasión.

16 I. MARTÍN DELGADO "La reclamación ante el consejo de transparencia y buen gobierno: ¿un instrumento necesario, útil y ¿eficaz?", XI Congreso de la AEPDA, 2016. 
A estas circunstancias debe añadirse lo que, en mi opinión, constituye un anomalía en el funcionamiento de la administración pública pero que se ha convertido en toda una institución de nuestro sistema: el silencio administrativo, que, en este ámbito y sin perjuicio de las regulaciones autonómicas en las que tiene carácter positivo, tendrá sentido desestimatorio de la solicitud.

\section{EL BUEN GOBIERNO EN CLAVE LOCAL: POLÍtICAS DE REGENERACIÓN DEMOCRÁTICA}

Uno de los ejes de la normativa estatal en materia de transparencia es precisamente el buen gobierno, título cuya entrada en vigor, frente a las regulaciones de publicidad activa y derecho de acceso a la información, se produjo con carácter inmediato, aunque transcurridos más de dos años la proyección práctica de esta regulación no parece demasiado eficaz, aunque puede observarse una cierta tendencia en las las últimas iniciativas normativas autonómicas que parecen estar reforzando la dimensión ética de la gestión pública ${ }^{17}$.

\subsection{Los códigos éticos o de conducta como instrumentos al servicio de la transparencia}

Los códigos éticos como instrumentos de autorregulación están adquiriendo cada vez mayor peso en el ámbito de la administración pública, y con un mayor recorrido en el ámbito local, para el cual alguna normativa autonómica, como la Ley 19/2014, de 29 de diciembre, se transparencia, acceso a la información y buen gobierno de la Generalitat de Cataluña, contempla la obligación de su aprobación, en la categoría de códigos de conducta ${ }^{18}$.

Bajo esta denominación se engloban diversas figuras, que si bien pueden compartir un sustrato común, han sido objeto de distinción terminológica, por su alcance y significado, identificando los códigos éticos con aquéllos que contienen principios o valores éticos, y códigos de buen gobierno con aquéllos que recogen pautas o criterios de organización, en tanto que los códigos de conducta contendrían las disposiciones que definen los comportamientos de los integrantes de la organización, sin perjuicio de admitir en dichas categorías los conocidos como códigos de buenas prácticas, aunque la realidad nos demuestra que los límites entre unos y otros son muy difusos ${ }^{19}$.

Aunque la simple codificación de principios éticos y estándares de conducta carece de fuerza vinculante para su observancia, y en consecuencia, para generar por sí solos un impacto positivo en el buen gobierno, no cabe duda de que están llamados a desempeñar un relevante

\footnotetext{
${ }^{17}$ Entre otros, el Proyecto de Ley de Integridad y Ética Pública de Aragón.

${ }^{18}$ Siendo destacables iniciativas con un amplio recorrido en el ámbito de la ética y de la integridad institucional como la experiencia del Ayuntamiento de Bilbao o de la Diputación Foral de Guipúzcoa

19 M. C. CAMPOS ACUÑA, "La dimensión ética en la gestión pública local: el Código de Buen Gobierno Local de la FEMP". Revista de administración práctica, Aranzadi, diciembre 2015.
} 
papel en la conformación de marcos de integridad institucional de la $\mathrm{OCDE}^{20}$ y que para una mayor eficacia pueden conjugarse a modo de las técnicas de compliance existentes en el sector privado, con profundo arraigo en la empresa y que en un adecuado proceso de adaptación pueden revelarse como eficaces instrumentos de mejora de la calidad democrática de las instituciones, estableciendo un completo sistema organizativo de control y seguimiento, como mecanismo de prevención de comportamientos ilícitos a través de un proceso de la interiorización de la dimensión ética en la gestión pública.

\subsection{El buen gobierno en la Ley de Transparencia}

A pesar de que la LETAI dedica íntegramente un título a la regulación del buen gobierno, no se ocupa de ofrecer una definición de dicha noción. Ante esta ausencia podemos compartir aquélla que afirma que el buen gobierno será aquél que promueve instituciones formales (normas y reglamentos) e informales (lógicas de lo apropiado en cada organización pública) que fomentan la transparencia, la rendición de cuentas, la eficacia, la coherencia y la participación. A ello habría que incorporar un quinto principio, el de integridad, y un sexto, el de la objetividad o imparcialidad en el servicio al interés general, inherente al funcionamiento de la administración y en nuestro caso, recogido en el propio artículo 103.01 de la Constitución española. El buen gobierno no se limita a crear las normas, sino a garantizar que las normas se hagan reales e implementables, generando los procesos adecuados a tal fin $^{21}$.

La normativa básica ha optado por otorgar rango de ley a los principios éticos y de actuación que deben regir la labor de los miembros del Gobierno y altos cargos y asimilados de la Administración General del Estado, de las comunidades autónomas y de las entidades locales, ante lo que no podemos obviar la dificultad de trasladar al ámbito jurídico normas morales, y sin negar la interrelación entre la ética pública y el derecho.

Aún así la opción del legislador ha sido la de incorporar íntegramente un Título II al Buen Gobierno (arts. 25 a 32), en una estructura que se articula sobre dos bloques, la determinación de su ámbito de aplicación y los principios reguladores, y un segundo bloque centrado en el ámbito sancionador, mediante el establecimiento de infracciones y sus correspondientes sanciones, desde una clasificación tripartita: en materia de conflicto de intereses, de gestión económico-presupuestaria e infracciones disciplinarias.

No obstante, el protagonismo normativo de la Administración General del Estado, ante el carácter básico de la LETAI, deteriora la claridad y seguridad jurídica en la aplicación de sus previsiones a las entidades que integran la administración local, obligando a los operadores jurídicos a realizar auténticos quiebros interpretativos en su aplicación. Las

\footnotetext{
20 A. IZQUIERDO SÁNCHEZ y M. VILLORIA MENDIETA. Ética pública y buen gobierno, Tecnos, Madrid, 2016.

21 M. VILLORIA MENDIETA, "Instituciones, buena gobernanza y buen gobierno: clarificando conceptos", Revista Democracia y Gobierno Local, núm. 20, 2013.
} 
dificultades derivadas del difícil encaje de este tipo de previsiones en una norma con carácter básico también fue objeto de una amplio debate durante la tramitación parlamentaria, que finalmente fue resuelto mediante la incorporación en la ponencia de la previsión de que cada administración aplicaría la ley en el ámbito de sus competencias, en una manifestación del debido respeto a las competencias organizativas y de funcionamiento tanto de los gobiernos autonómicos como locales.

\section{EL IMPACTO DE LA NORMATIVA AUTONÓMICA EN LA TRANSPARENCIA LOCAL}

A la entrada en vigor de la LETAI ya algunas comunidades autónomas habían anticipado su propia normativa en materia de transparencia, entre ellas Galicia, que aportaba la norma de mayor antigüedad, la Ley 4/2006, de 30 de junio, de transparencia y de buenas prácticas en la Administración pública gallega, derogada por la LGT. Se suma así Galicia a la actividad legislativa en esta materia de otras comunidades que, tras la entrada en vigor de la normativa básica estatal se lanzaron a una intensa regulación tanto de aspectos relativos a la transparencia como a la dimensión ética.

Transcurridos diez años desde la aprobación de la primera norma gallega, la LGT aborda una revisión integral de la normativa, desde un enfoque más amplio al dotarla de mayor alcance al introducir nuevos contenidos regulatorios, como los relativos al gobierno en funciones y a las actuaciones de traspaso de poderes, etapa necesitada de unas normas mínimas que garanticen la salvaguarda del interés público, en ausencia, en ocasiones, del sentido de la responsabilidad de aquéllos que abandonan el gobierno, y que representan una apuesta por el buen gobierno.

\subsection{Las entidades locales como sujetos activos de la transparencia autonómica}

La normativa gallega, a diferencia del modelo normativo de la mayoría de las comunidades autónomas no recoge a las entidades locales en su ámbito subjetivo ${ }^{22}$, por lo que su régimen en materia de transparencia, acceso a la información pública y buen gobierno se circunscribirá a lo dispuesto en la normativa básica estatal, sin perjuicio de la existencia de más impactos de los que a primera vista podrían detectarse, como, en particular, la tramitación de los procedimientos de reclamación previa en materia de acceso a la información, tal y como examinaremos a continuación.

\footnotetext{
${ }^{22} \mathrm{Y}$ a diferencia de otras que sí han incluido a las entidades locales en su ámbito subjetivo, como la Ley $8 / 2015$, de 25 de marzo, de transparencia de la actividad pública y participación ciudadana de Aragón, la Ley 1/2014, de 24 de junio, de transparencia pública de Andalucía, la Ley 19/2014, de 29 de diciembre, de transparencia, acceso a la información pública y buen gobierno de Cataluña, la Ley 12/2014, de 26 de diciembre, de transparencia y de acceso a la información pública de Canarias, o la Ley 2/2015, de 2 de abril, de transparencia, buen gobierno y participación ciudadana de la Comunitat Valenciana.
} 
La falta de aplicación a las entidades locales gallegas de la normativa autonómica impide suplir de este modo una trascendental carencia de la normativa básica, como es la falta de regulación de régimen sancionador frente a los eventuales incumplimientos normativos, deficiencia que afecta tanto a las obligaciones relativas a la publicidad activa como a la pasiva. Esta situación no se produce en aquellas comunidades autónomas que sí recogen en su ámbito subjetivo a las entidades locales, pues contemplan ya las previsiones en materia sancionadora

\subsection{Especial referencia a la Ley $1 / 2016$, de Transparencia y Buen Gobierno de Galicia (LGT)}

Las entidades locales entablan un amplio catálogo de relaciones con el sector público autonómico, dentro del cual podemos destacar la actividad convencional y el ámbito de las subvenciones, en su calidad de perceptoras de las mismas, razón por la cual deben tomarse en consideración, con carácter general, las previsiones recogidas en el art. 15 LGT sobre convenios y en el art. 17 LGT en materia de subvenciones.

Una de las especialidades de aplicación a las entidades locales de la configuración gallega se produce en relación con el derecho de acceso a la información, en particular, en lo relativo a la tramitación de la reclamación potestativa previa recogida en el art. 24 LETAI, conforme a lo establecido en la Disposición Adicional Quinta de la LGT, conforme a la cual la resolución de dichas resoluciones corresponderá en el supuesto de resoluciones dictadas por las entidades locales de Galicia, al Valedor del $\mathrm{Pobo}^{23}$.

Conforme al estudio "Abriendo puertas y ventanas de los ayuntamientos gallegos. Más transparencia para un mejor gobierno local" de Red Localis ${ }^{24}$, las entidades locales gallegas no se encuentran en condiciones óptimas de implantación de las obligaciones legales en materia de transparencia, por lo que resulta necesario arbitrar medidas que faciliten el cumplimiento, algunas de las cuales pueden considerarse recogidas en la normativa autonómica, en particular, en relación con la creación de redes interadministrativas para aprovechar las sinergias derivadas de estrategias de actuación conjuntas, como veremos en el siguiente apartado en relación con el espacio de transparencia Eidolocal.

Asimismo, la Disposición adicional primera LGT contempla una previsión fundamental para garantizar el éxito en el proceso de implantación de la transparencia, relativa a la formación del personal público, al contemplar

23 J. J. FERNÁNDEZ RODRÍGUEZ y D. NEIRA BARRAL consideran poco oportuna la atribución del control de la transparencia a un órgano como el Valedor do Pobo de Galicia, aunque con un matiz, pues afirman que si bien no sería acertado atribuírsela en exclusiva, sí podría resultar conveniente una posición mixta de control, sin que ello perjudicara la posición de órgano garante en un hipotético procedimiento de control, que podría materializarse, por ejemplo, mediante una supervisión externa de la actividad, en "El papel de las defensorías del pueblo en el control de la transparencia y el acceso a la información", Comunicación presentada al VI Congreso Internacional en Gobierno, Administración y Políticas Públicas, GIGAPP IUIOG, 2015.

24 J. CAAMAÑO ALEGRE y M.C. CAMPOS ACUÑA 
que la Escuela Gallega de Administración Pública incorporará, dentro de su plan de formación, instrumentos específicos para formar al personal empleado público en los derechos y obligaciones regulados por la LGT.

El "Espacio de transparencia" es el resultado de la colaboración de la Dirección Xeral de Administración Local, la Federación Gallega de Municipios y Provincias y la Axencia para a Modernización Tecnolóxica de Galicia, que ofrece una doble virtualidad, la de facilitar a las entidades locales una plataforma para cumplir con las obligaciones de publicidad que les exige la Ley de Transparencia y a su vez, proporcionar a la ciudadanía una herramienta de consulta de la información relativa a la actividad de las entidades locales gallegas.

El diseño del espacio de transparencia estructura la información a través de seis ámbitos:

- Institución, organización, planificación y personal

- $\quad$ Altos cargos y personal directivo

- Jurídica y patrimonial

- $\quad$ Contratación, convenios y subvenciones

- Económico, financiera y presupuestaria

- $\quad$ Servicios y procedimientos

Se configura como una herramienta flexible pues pretende adaptarse a las distintas necesidades de cada entidad local, articulando una doble fórmula colaborativa. Por un lado, para aquellas entidades locales que tengan la información publicada de forma no estructurada, diseminada en su página web, la utilización del espacio transparencia de Eidolocal permitirá su publicación de una forma organizada. Por otro, las entidades locales que no dispongan de ningún medio para publicar la información al respecto, podrán utilizar el espacio transparencia cumplimentando sus secciones y subsecciones, con los datos correspondientes.

\section{RETOS DE FUTURO PARA LOS GOBIERNOS LOCALES}

Como hemos dicho, el Estudio "Abriendo puertas y ventanas de los ayuntamientos gallegos. Más transparencia para un mejor gobierno local" de Red Localis de 2015, ha puesto de manifiesto que las entidades locales gallegas no se encuentran en condiciones óptimas de implantación de las obligaciones legales en materia de transparencia, suspendiendo en promedio el cumplimiento normativo, por lo que resulta necesario arbitrar medidas que faciliten el cumplimiento, algunas de las cuales pueden considerarse recogidas en la normativa autonómica, en particular, en relación con la creación de redes interadministrativas para aprovechar las sinergias derivadas de estrategias de actuación conjuntas.

Para ello y entre el decálogo de propuestas para la implantación diagnosticados en el citado estudio de Red Localis, sobre la base de los datos recogidos entre las propias entidades locales gallegas, pueden apuntarse tres ejes que abordaremos en los siguientes apartados:

1. Implantación definitiva de la administración electrónica. Objetivo claramente impuesto por la reforma administrativa a través de la Ley $39 / 2015$, de 1 de octubre, del procedimiento administrativo 
común de las administraciones públicas, y de la Ley 40/2015, de 1 de octubre, de régimen jurídico del sector público.

2. Apostar por la reutilización de datos (open data) como una vía para generar valor público y transmitirlo a la sociedad.

3. Desarrollo del gobierno abierto y participación ciudadana, como una vía para recuperar la legitimidad democrática de los responsables políticos y la confianza ciudadana en las instituciones públicas.

\subsection{La transformación digital: sinergias derivadas de la reforma} Como hemos expuesto, la aprobación de la Ley 39/2015, de 1 de octubre, del procedimiento administrativo común de las administraciones públicas, y la Ley 40/2015, de 1 de octubre, de régimen jurídico del sector público, se encuentra ampliamente conectada con los objetivos de la transparencia a través de un elemento común: la administración electrónica. En octubre de 2016, las entidades locales, todas con independencia de su tamaño y recursos, estarán obligadas a la tramitación íntegramente electrónica de sus expedientes.

La sinergia normativa que coadyuva al cumplimiento de los objetivos de la transparencia puede afirmarse desde una doble perspectiva: formal y material. Desde un punto de vista formal, a través de las dos normas que concentran la reforma administrativa se invoca como una constante a la transparencia, como nuevo principio regulador y de actuación. En la propia Exposición de Motivos de la Ley 39/2015, de 1 de octubre, del procedimiento administrativo común de las administraciones públicas, se señala la aprobación de la LETAI como una de las causas que aconsejan la reforma, y su incorporación como principio regulador se produce tanto a nivel organizativo y de funcionamiento de las Administraciones Públicas, en la Ley 40/2015, de 1 de octubre, de régimen jurídico del sector público, así como uno de los ejes de la mejora de la calidad normativa impuesta por el nuevo Título VI de la Ley 39/2015, de 1 de octubre, del procedimiento administrativo común de las administraciones públicas.

Desde un punto de vista material, la vinculación se produce a través de la conexión de la administración electrónica en el cumplimiento de la LETAI en su doble vertiente: publicidad activa y pasiva. La publicidad activa sólo se puede ejercer on line, a través de la página web o sede electrónica de la respectiva entidad local, y la publicidad pasiva, se ejercerá preferentemente por vía electrónica. Pero tanto en uno como en otro caso, la implantación definitiva de la administración electrónica a través de un gestor de expedientes, y un adecuado sistema de política documental serán claves para ofrecer la información de forma clara, estructurada y accesible. Así lo afirma la propia Exposición de Motivos de la Ley 39/2015, de 1 de octubre, del procedimiento administrativo común de las administraciones públicas, cuando señala que la constancia de documentos y actuaciones en un archivo electrónico facilita el cumplimiento de las obligaciones de transparencia, pues permite ofrecer información puntual, ágil y actualizada a los interesados.

En este aspecto la Ley $39 / 2015$, de 1 de octubre, del procedimiento administrativo común de las administraciones públicas, conserva el 
derecho de acceso en el catálogo de derechos de los ciudadanos en el artículo $13 \mathrm{~d}$ ), con la regulación anterior: "d) Al acceso a la información pública, archivos y registros, de acuerdo con lo previsto en la LETAI y el resto del ordenamiento jurídico", concretado en el artículo 53 para los que ostenten la condición de interesados en el procedimiento.

\subsection{La reutilización de datos como vía para generar valor público}

La Ley $37 / 2007$, de 16 de noviembre, sobre reutilización de la información del sector público, contempla el régimen jurídico aplicable a la reutilización de los documentos elaborados o custodiados por las administraciones y organismos del sector público. Aunque no se trata de una materia directamente regulada en la LETAI, sí se establece una clara referencia a ella al establecer la publicación preferente de la información en formatos reutilizables, elemento fundamental para favorecer una verdadera rendición de cuentas (accountability)

Se entiende por reutilización el uso de documentos que obran en poder de las Administraciones y organismos del sector público, por personas físicas o jurídicas, con fines comerciales o no comerciales, siempre que dicho uso no constituya una actividad administrativa pública. Queda excluido de este concepto el intercambio de documentos entre administraciones y organismos del sector público en el ejercicio de las funciones públicas que tengan atribuidas. Noción que se aplica a los documentos elaborados o custodiados por las administraciones y organismos del sector público, cuya reutilización no esté expresamente limitada por éstos ${ }^{25}$.

La Ordenanza Tipo de la Federación Española de Municipios y Provincias, de transparencia, acceso a la información y reutilización, incluye el desarrollo reglamentario de esta materia ante la percepción de su importancia para la consecución de los objetivos del gobierno abierto. Para ello dedica su capítulo $\mathrm{V}$ a la transparencia colaborativa, regulando el régimen de reutilización de la información pública, cuyo objetivo fundamental es la generación de valor público en la ciudadanía en los ámbitos social, innovador y económico ${ }^{26}$.

\subsection{El desarrollo del gobierno abierto a través de la participación ciudadana}

En el ámbito local, el principio de proximidad, tan característico de este nivel de organización territorial, ha tenido su reflejo en la configuración de las entidades locales como cauces directos de participación ciudadana. La propia Ley $7 / 1985$, de 2 de abril, reguladora de las bases de régimen local, contempla en su Título $\mathrm{V}$ "Disposiciones comunes a las entidades

\footnotetext{
${ }^{25}$ La apertura de datos a través de la reutilización de la información del sector público ofrece indudables beneficios para la rendición de cuentas, en todos los aspectos de la gestión pública, y, en particular, respecto a áreas especialmente sensibles a la corrupción, tal y como señala A. CERRILLO I MARTÍNEZ "Las compras abiertas y la prevención de la corrupción", Gestión y análisis de políticas públicas, núm. 15, 2016.

26 Disponible en http://www.femp.es/files/11-5133fichero/Ordenanza\%20Transparencia,\%20Acceso $\% 20$ y\%20Reutilización $\% 20$ de $\% 201 a \% 2$ Oinformación.pdf
} 
locales", un Capítulo dedicado exclusivamente a la información y participación ciudadana que impone un nutrido conjunto de obligaciones.

De ahí que el ámbito local resulta idóneo para el desarrollo de políticas públicas en materia de transparencia orientadas a la transformación del modelo de gobierno, hacia el gobierno abierto. Gobierno abierto que podemos definir como una "filosofía político administrativa", que articula un modelo distinto de interacción sociopolítica, y que, basado firmemente en los valores y principios de la transparencia, de la democracia participativa, del empoderamiento ciudadano, de la rendición de cuentas, del open data y del uso de avances tecnológicos, se constituye como un modo y/o estrategia para el diseño, implementación, control y evaluación de políticas públicas (incluidas las de modernización administrativa), que ubica al ciudadano en el centro de atención y de prioridad y configura los gobiernos como plataformas que promueven la colaboración e interacción, ofreciendo así una alternativa holística para la gestión de lo público ${ }^{27}$.

Desde esta óptica la Ley $7 / 1985$, de 2 de abril, reguladora de las bases de régimen local, contempla la obligación de las entidades locales de facilitar la más amplia información sobre su actividad y la participación de todos los ciudadanos en la vida local, sin que las formas, medios y procedimientos de participación que las corporaciones establezcan en ejercicio de su potestad de autoorganización no podrán en ningún caso menoscabar las facultades de decisión que corresponden a los órganos representativos regulados por la Ley $^{28}$.

Los avances en materia del gobierno abierto en el ámbito local, al margen de la estrategia de la "Alianza para el Gobierno Abierto", puede comprobarse también en la normativa sobre régimen local, como el citado Título VI "Gobierno abierto. Transparencia, datos abiertos y participación ciudadana" de la normativa vasca, de extenso contenido en el que se regula en profundidad esta materia, con especial incidencia en materia de participación ciudadana, regulando con amplitud las obligaciones de las entidades locales ante la definición de un modelo de gobierno abierto, estableciendo los procesos participativos para aproximar a la ciudadanía a los procesos de toma de decisiones y promoviendo un mayor nivel de

\footnotetext{
${ }^{27}$ C. CRUZ RUBIO. "Hacia el gobierno abierto: una caja de herramientas", Organización de los Estados Americanos, Washington.

${ }^{28}$ Conforme a lo establecido en el artículo 70.bis. 1 Ley 7/1985, de 2 de abril, reguladora de las bases de régimen local "Los ayuntamientos deberán establecer y regular en normas de carácter orgánico procedimientos y órganos adecuados para la efectiva participación de los vecinos en los asuntos de la vida pública local, tanto en el ámbito del municipio en su conjunto como en el de los distritos, en el supuesto de que existan en el municipio dichas divisiones territoriales. Asimismo, las entidades locales $y$, especialmente, los municipios, deberán impulsar la utilización interactiva de las tecnologías de la información y la comunicación para facilitar la participación y la comunicación con los vecinos, para la presentación de documentos y para la realización de trámites administrativos, de encuestas y, en su caso, de consultas ciudadanas. Las Diputaciones provinciales, Cabildos y Consejos insulares colaborarán con los municipios que, por su insuficiente capacidad económica y de gestión, no puedan desarrollar en grado suficiente el deber establecido en este apartado".
} 
rendición de cuentas a través de la transparencia, en su doble dimensión, publicidad activa y derecho de acceso a la información pública.

En definitiva, partiendo de la premisa del carácter instrumental de la transparencia, como medio para alcanzar un fin, el gobierno abierto, será necesario redoblar esfuerzos, en general, y, en particular, en el ámbito local, para alcanzar un nivel de mínimos satisfactorio, que permita iguales condiciones de acceso a la ciudadanía frente a todas las Administraciones Públicas y materializar la rendición de cuentas y la regeneración democrática demandada por la sociedad.

\section{BIBLIOGRAFÍA}

ALMEIDA CERREDA, M., "La reforma de la planta, organización, articulación y estructura competencial de la administración local", VIII Congreso Asociación Española de Profesores de Derecho Administrativo, 2013.

CAMPOS ACUÑA, M. C., "Las entidades locales ante las obligaciones de transparencia. Una primera aproximación a la Ley 19/2013, de transparencia, acceso a la información pública y buen gobierno", Revista electrónica CEMCI, núm. 22, 2014. http://revista.cemci.org/numero-23/pdf/tribuna-2-las-entidadeslocales-ante-las-obligaciones-de-transparencia.pdf

CAMPOS ACUÑA, M. C., "Obligaciones de publicidad activa y su traslación al ámbito local. De la teoría a la práctica", Consultor de los ayuntamientos, Monográfico dedicado a la transparencia en la actividad municipal (M. C. CAMPOS ACUÑA, coord.), núm. 18, 2015, pp. 2067-2083.

CAMPOS ACUÑA, M. C., "Implantación de la Ley 19/2013 ¿Cirugía o maquillaje? Claves para el diseño de una estrategia de transparencia", Consultor de los ayuntamientos, Monográfico dedicado a la transparencia en la actividad municipal (M. C. CAMPOS ACUÑA, coord.), núm. 18, 2015, pp. 2231-2248.

CAMPOS ACUÑA, M. C., "La dimensión ética en la gestión pública local: El Código de Buen Gobierno Local de la FEMP", Revista de administración práctica, Aranzadi, diciembre 2015.

CAMPOS ACUÑA, M. C., "Códigos éticos y Buen Gobierno Local en la Ley de Transparencia", Revista Vasca de Gestión de Personas y Organizaciones Públicas, Monográfico sobre Códigos éticos, IVAP, $2015 . \quad$ https://www.euskadi.net/r61-

s20001x/es/t59aWar/t59aMostrarFicheroServlet?t59aIdRevista $=3 \&$ R $01 \mathrm{HNoPortal}=$ true\&t59aTipoEjemplar=R\&t59aSeccion=52\&t59aCont enido $=1 \&$ t59aCorrelativo $=1 \&$ t59aVersion $=2 \&$ t59aNumEjemplar $=9$

CAMPOS ACUÑA, M. C., "Ley 1/2016, de enero, de Transparencia y Buen Gobierno de Galicia. Impacto y repercusión en el ámbito local", El Consultor de los Ayuntamientos, núm. 5, 2016, pp. 502-516.

CAAMAÑO ALEGRE, J. y CAMPOS ACUÑA, M. C., "Abriendo puertas y ventanas de los ayuntamientos gallegos. Más transparencia para un mejor gobierno local", Red Localis, 2015. 
http://media.wix.com/ugd/60c8a3_22b9d2961df548999bcb41d1f2cfb270. pdf

CERRILLO I MARTÍNEZ, A., "Las compras abiertas y la prevención de la corrupción", Revista Gestión y análisis de políticas públicas, núm. $15,2016$.

FERNÁNDEZ RODRÍGUEZ, J. J. y NEIRA BARRAL, D., "El papel de las defensorías del pueblo en el control de la transparencia y el acceso a la información", Comunicación presentada al VI Congreso Internacional en Gobierno, Administración y Políticas Públicas, GIGAPP IUIOG, 2015.

http://www.gigapp.org/administrator/components/com_jresea rch/files/publications/2015-A03-NEIRAFERNANDEZ.pdf

GUICHOT REINA, E., Transparencia, Acceso a la Información Pública y Buen Gobierno, Tecnos, Madrid, 2014.

GUICHOT REINA, E., "Derecho de acceso a la información pública en el ámbito local", Consultor de los ayuntamientos, Monográfico dedicado a la transparencia en la actividad municipal (M. C. CAMPOS ACUÑA, coord.), núm. 18, 2015, pp. 1983-2001.

GUICHOT REINA, E., "Transparencia y acceso a la información pública en el marco de la lucha contra la corrupción" en J.M. Gimeno Feliu, J. Tejedor Bielsa y M. Villoria Mendieta (dirs.), La corrupción en España, Atelier, Barcelona, 2016.

IZQUIERDO SÁNCHEZ, A., y VILLORIA MENDIETA, M., Ética pública y buen gobierno, Tecnos, 2016.

MARTÍN DELGADO, I., "La reclamación ante el consejo de transparencia y buen gobierno: un instrumento necesario, útil y ¿eficaz?", XI Congreso de la AEPDA, 2016.

RAZQUIN LIZARRAGA, M. M., El derecho de acceso a la información pública, IVAP, Oñati, 2015.

PRIETO ROMERO, C., "Medidas de transparencia y ética pública: los códigos éticos, de conducta o de buen gobierno", Anuario del Gobierno Local, 2011.

RAMS RAMOS, L., "La transformación del derecho de acceso en España: de derecho de configuración legal a derecho fundamental", Revista Española de Derecho Administrativo, Cívitas-Thomson Reuters, núm. 160, 2013.

VILLORIA MENDIETA, M., "El largo camino hacia la transparencia en los Ayuntamientos españoles", Consultor de los ayuntamientos, Monográfico dedicado a la transparencia en la actividad municipal (M. C. CAMPOS ACUÑA, coord.), núm. 18, 2015, pp. 1983-2001.

VILLORIA MENDIETA, M, "Instituciones, buena gobernanza y buen gobierno: clarificando conceptos", Revista Democracia y Gobierno Local, núm. 20, 2013. 